\title{
Comparative aspects of conceptus growth: a historical perspective*
}

\author{
Keith J. Betteridge \\ Department of Biomedical Sciences, Ontario Veterinary College, University of Guelph, \\ Guelph, Ontario, N1G 2W1, Canada
}

\begin{abstract}
This review provides a historical background for a series of articles arising from a symposium on Early Regulation of Mammalian Development. It begins by tracing connections between the work of J. Cossar Ewart and the first cloning of mammals by somatic cell nuclear transfer. Historical scientific landmarks over the last century that have affected our attitudes to 'fetal autonomy' and conceptus development are reviewed briefly, as are salient studies that have established the importance of nutrition to pre- and postnatal life. Finally, attention is drawn to some differences in conceptus development among various mammals, and the argument made that understanding these differences might be of benefit to the development of reproductive technology.
\end{abstract}

Problems encountered during the application of the 'new' reproductive techniques have focused attention on embryos and fetuses as never before. In addition, there has been a growing acceptance of the fact that the environment experienced by the embryo and fetus in vitro and in utero has effects that persist into adulthood and subsequent generations. Mammalian embryos also serve as models for the study of fundamental questions about the control of the growth, differentiation and size of cells, tissues, organs and animals (Conlon and Raff, 1999), which have a bearing on clinical topics as diverse as neoplasia and xenotransplantation. Consideration of the embryo and its membranes as a model system can, in turn, benefit from an appreciation of interspecies similarities and differences in conceptus growth. The three objectives of the present article are: (1) to provide a historical background for the ways in which conceptus development is regarded, and how these attitudes relate to the new reproductive techniques; (2) to provide a similar perspective on our attitudes to the effects of nutrition on the conceptus; and (3) to draw attention to reproductive phenomena in a variety of mammals which, if understood, could advance understanding of early mammalian development in general and the solution of problems arising from the new reproductive techniques in particular.

\section{Historical attitudes to conceptus development}

Making use of embryology to further understanding of other aspects of science is by no means new. James Cossar Ewart

Email: kbetter@uoguelph.ca

*This article is the first of a series based on presentations given at the symposium 'Early Regulation of Mammalian Development' held in Aberdeen in September 2000 and organized by the British Society of Animal Science. was appointed Regius Professor of Zoology and Comparative Anatomy in Aberdeen University's Medical School in 1878. In his introductory lecture, in 1879, Ewart spoke of '...embryologists - headed by Von Baer - who through working out the individual development of animals have rendered possible the attempt to make out their ancestral history' (Ewart, 1879). Thus, the usefulness of embryology as a tool of investigation was under discussion more than 120 years ago. Since it was Karl Ernst Von Baer who first discovered the mammalian egg (from a dog in 1827; see Betteridge, 1981), and considering that it was his friend Karl Friedrich Burdach (owner of that unfortunate dog) who is credited with coining the term 'biology', this use of embryology can be said to be as old as reproductive biology. It is therefore remarkable that using embryology as a research tool to cast light on phylogeny still has its uses (Gaeth et al., 1999).

Ewart became much more interested in embryological studies for studying phylogeny after his appointment to the Chair of Natural History at the University of Edinburgh in 1882 - a position that he was to hold for 45 years. Intrigued by an extra digit on the foot of a foal brought into him by a student, Ewart began to collect horse conceptuses to determine whether an ancestral three-toed condition was reflected during normal fetal development (Anon, 1896). Ewart's comparative descriptions of his collection (Ewart, $1897,1915)$ still demand attention but, ironically, it was for his investigations of telegony - as a sideline to his embryological work - that Ewart became best known (Ewart, 1899). The paper published in 1897 is especially notable for its comparative descriptions and discussion of early embryonic development in horses, marsupials and birds, and for its first description of the equine chorioallantoic girdle - the structure that, many years later, became an important marker of 'fetal autonomy'.

For his famous Penycuik Experiments on telegony, Ewart 


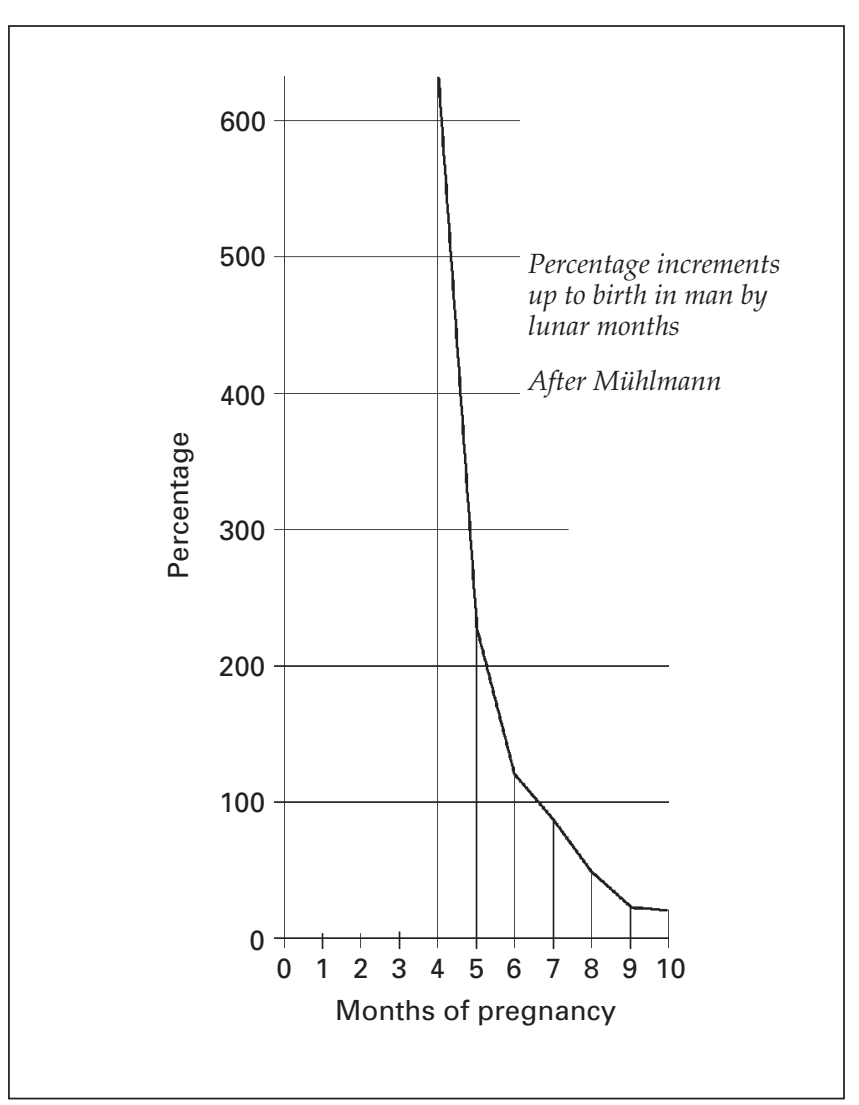

Fig. 1. Decline in rates of growth as pregnancy progresses. (Redrawn from Minot, 1908.)

hired F. H. A. Marshall, who later wrote the first textbook on reproductive physiology (1910) and founded a dynasty of scientists involved in fundamental and applied aspects of embryo work at Cambridge. Furthermore, Ewart's lobbying led to the founding of animal breeding institutes of which Roslin, birthplace of Dolly, is a descendant.

Besides providing an authoritative account of how conceptus development was viewed a century ago, the first edition of Marshall's Physiology of Reproduction refers the reader to Charles Sedgwick Minot's The Problem of Age, Growth, and Death (1908) - a collection of lectures as worth reading for their vivid prose as for their insightful content. Minot was the James Stillman Professor of Comparative Anatomy at the Harvard Medical School. Several points about his experimental studies, mostly in guinea-pigs, and his extrapolations to other species (including humans) are particularly relevant to the evolution of our current attitudes to conceptus development. First, there is his emphasis on the continuity of pre- and postnatal life reflected, for example, in growth patterns. For those of us accustomed to thinking of fetal growth as increasing steadily (in relation to pregnancy diagnosis, for example, Betteridge and Laing, 1970) it is salutary to be told by Minot that 'Over 98 per cent of the original growth power of the rabbit or of the chick has been lost at the time of birth or hatching, respectively, and the same thing is equally true of man. We start out at birth certainly with less than two per cent of the original growth power with which we were endowed.' This 'rather unexpected conclusion' astonished Minot, being '...so different from our conclusions based on our acquaintance with the growth and progress of the individuals about us'. Minot's point, which was illustrated in The Problem of Age, Growth, and Death and reproduced in Marshall's Physiology of Reproduction (redrawn in Fig. 1 ), has since been substantiated with rather more precision (Robinson, 1977). It was this decline in 'growth power' with age that led Minot to the conclusion that '...not from the study of the old, therefore, but from the study of the very young, of the young embryo, and of the germ, are we to expect insight into the complicated questions we have begun to consider together'.

This conclusion remains a rational principle for tackling the investigation of ageing, which Hayflick (2000) has suggested is 'an artefact of civilization'. Minot can be credited with considerable prescience for his ideas of how the nuclear:cytoplasmic ratio of a cell influences its growth and differentiation, and of how '...the process of segmentation of the ovum, with which the development of all the animals of the higher type invariably begins, is really the process of producing young cells. It is the process of rejuvenation'.

The first decade of the twentieth century also saw the first endocrinological studies, including a study that demonstrated that the conceptus produces and responds to 'internal secretions' (Bouin and Ancel, 1903). The era of urinary and serum gonadotrophin discoveries in humans and horses during the 1920s and 1930s (Hamburger, 1965; Greep, 1973) is of special relevance to the growth of the concept of 'fetal autonomy' - the appreciation of the mammalian fetus as an active participant in pregnancy rather than a mere passenger in the uterus. The realization that gonadotrophins in the urine of pregnant women are the products of the conceptus, and the consequent naming of human chorionic gonadotrophin (hCG), was an early discovery. The corresponding story in mares is more convoluted. Gonadotrophic activity was first detected in the serum rather than the urine of pregnant mares and therefore named pregnant mares' serum gonadotrophin (PMSG). Later, it was discovered that PMSG activity (biologically different from that of hCG) could be recovered from endometrial cups, the ulcerous structures that form opposite the chorioallantoic girdle of the conceptus. Assays of PMSG, developed primarily as a means of diagnosing pregnancy, also showed that the concentrations found in serum between day 40 and day 120 of pregnancy varied considerably from mare to mare. Investigations of horse $x$ donkey hybrid pregnancies in Poland first revealed that this variation is controlled genetically (Bielanski et al., 1955). However, it was not until the extensive studies of Allen and colleagues in Cambridge during the 1970s that it became apparent that the genetic variation in gonadotrophin production is attributable to the fact that the hormone is of 
fetal origin (Allen, 1982). Consequently, PMSG is now more usually called equine chorionic gonadotrophin (eCG).

Despite the early attribution of hCG to its fetal source, the tendency to regard the fetus as a passive rather than active participant in pregnancy prevailed until the 1960s, when at least two important symposia (Perry, 1969; Wolstenholme and O'Connor, 1969) summarized the accumulating evidence for fetal autonomy. The evidence emanated largely from studies of the initiation of parturition, sexual differentiation, and of the 'recognition of pregnancy' at the time that luteolysis would otherwise supervene in the non-pregnant animal. Autonomous activity is easier to envisage in a term fetus than in a cleaving embryo, and therefore evidence for the active role of fetuses and embryos in pregnancy tended to accumulate first from studies of the later stages of pregnancy and then spread gradually backwards to earlier stages of pregnancy.

The role of the mammalian fetus in determining when parturition should begin was demonstrated in the late $1950 \mathrm{~s}$ and the 1960s. Clinical observations of prolonged pregnancies in humans (for review, see Longo, 2000) and domestic animals (for review, see Holm, 1967) led to speculation that the initiation of parturition depends upon an intact hypothalamo-pituitary-adrenal axis in the fetus (for example, see Holm and Short, 1962). Classic endocrinological experimentation in sheep (Liggins et al., 1967) confirmed this contention (although maternal factors are now known to determine the time of day that birth occurs; Nathanielsz, 1998). The significance of the study by Liggins et al. (1967) has been commemorated, together with a concise history of the observations preceding it (Longo, 2000). G. S. Dawes, in his opening remarks to the first of the two symposia referred to above (Wolstenholme and O'Connor, 1969), stated that 'Work ... [was] in progress by investigators separated not just by distance but even more by discipline, who publish in the journals of very different learned societies, and who very rarely meet together to exchange information of common interest. There still remains a large, almost unexplored territory between the embryologist and the foetal physiologist'. Dawes saw parts of that gap significantly reduced within 5 years at a further Ciba Symposium (Elliott and Knight, 1974), at which the emphasis was on disturbances of normal fetal autonomy leading to difference in size at birth. Especially relevant are the papers by Widdowson (1974) and Alexander (1974). Alexander (1974) reports some of the earliest observations of the vulnerability of oversized (as well as undersized) newborn lambs (Fig. 2), and on the effects of experimental manipulation of the cotyledonary placenta. Both Widdowson (1974) and Alexander (1974) describe early research into the differential growth of organs in fetuses in which growth is retarded, a topic central to current investigations of fetal oversize after embryo manipulation (for review, see Robinson et al., 1999).

Research into the mechanisms of sexual differentiation, particularly by Alfred Jost (described in Perry (1969) and Wolstenholme and O'Connor (1969)) provided incontro-

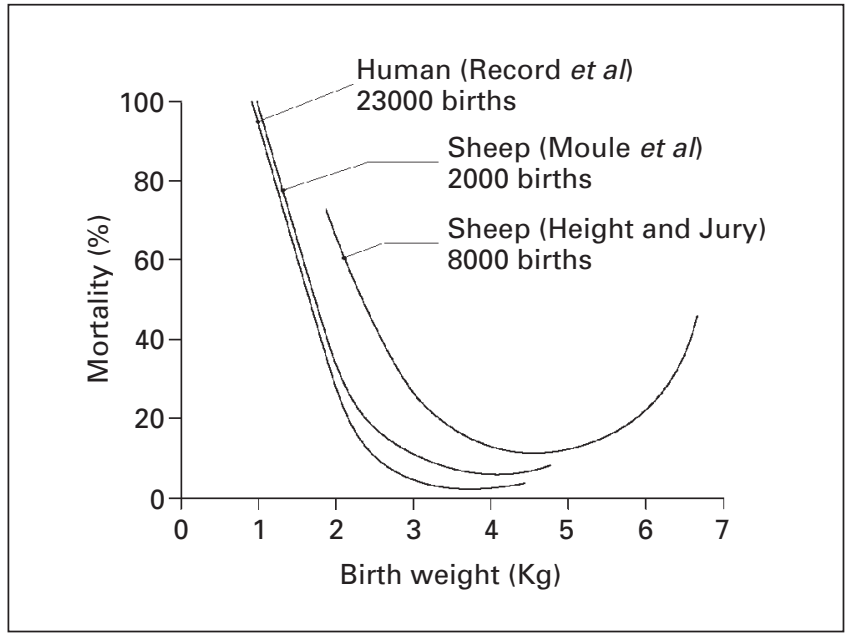

Fig. 2. Relationship, in lambs and human infants, between birth weight and mortality within the first weeks of life: smoothed curves from the data of Record et al. (1952), Moule et al. (1956) and Hight and Jury (1969). (Redrawn from Alexander, 1974.)

vertible evidence that fetuses have autonomous endocrine systems at stages much earlier than term. However, even at these earlier stages, the concept was still easy to accept, since the the fetal gonads and target organs involved could be recognized. The fact that sexual differentiation occurs over a rather long period also provides an illustration of the important general principle that the phenotypic effects of a disruption in a developmental process will depend very much on the timing and duration of the disruption (Neumann et al., 1969; Fig. 3).

The next earliest developmental stage to provide evidence of an active role for the conceptus was the socalled 'critical period' for the 'recognition of pregnancy' terms that originated at the 1969 symposium on fetal autonomy (Wolstenholme and O'Connor, 1969). The enormous attention that has been paid to this stage over the past 30 years has been something of a double-edged sword, leading some to ignore the fact that the periods before and after the time that luteolysis is prevented in some mammals are no less 'critical' for the establishment and maintenance of pregnancy. This attention may also have encouraged a search for common reproductive strategies among species where none are to be found. However, the results from studies of the 'critical period' have been extremely important in cementing the notion that very small conceptuses, at stages before organogenesis occurs, are capable of influencing the physiological functions of very large mothers. Furthermore, research in this area has identified an evergrowing range of compounds that conceptuses use as signals (received and sent) in their essential dialogue with their mother. These compounds include steroids, eicosanoids, interferons, platelet-activating factor, cytokines, an embryospecific tetrapeptide with biological activity (Kent, 1978; Cupo et al., 1987) and, perhaps, ATP (Leese et al., 2001). The enormous literature on these signals and their reception 


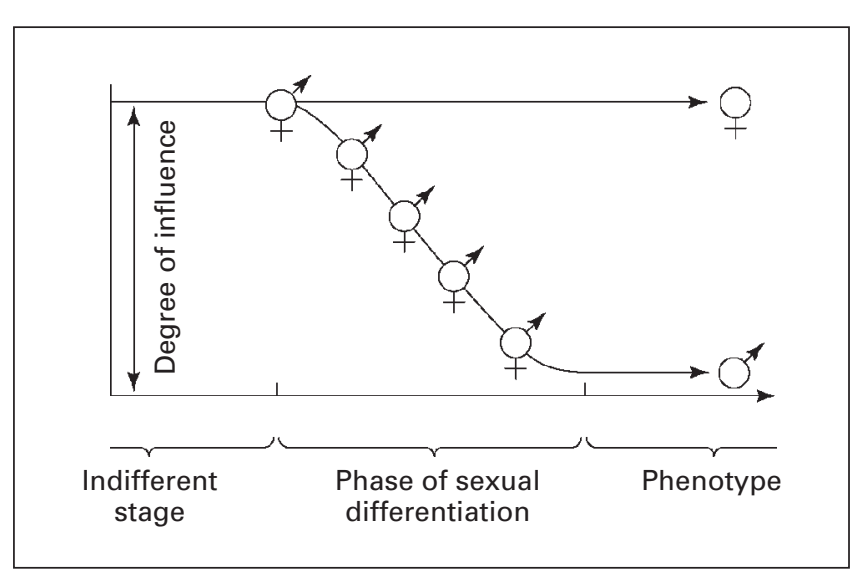

Fig. 3. The time factor in sexual differentiation. (Redrawn from Neumann et al., 1969.)

is beyond the scope of this article but two items of comparative and historical interest in this connection deserve more attention than they were accorded at the time.

In cattle, Hammond (1939) had clearly envisioned an active role (albeit luteotrophic rather than antiluteolytic) for the conceptus in abrogating luteolysis decades before that role was finally demonstrated. In horses, the observation by van Niekerk and Gerneke (1966) that unfertilized eggs are retained differentially in the oviduct was greeted with scepticism for years before being substantiated and leading to analogous findings in other species, too (for review, see Betteridge, 2000).

Pharmaceutical studies have also played a major role in shaping our attitudes to, and understanding of, conceptus development. The thalidomide and diethylstilboestrol tragedies underlined the sensitivity of organogenesis and the danger of transgenerational effects. Conversely, the potential benefits of maternal treatments have been demonstrated by the dietary use of folic acid to reduce the incidence of spina bifida (Anon, 1991). Studies in mice with the mutagen methylnitrosourea (MNU; lannacconne, 1984) demonstrated that long intervals may occur between the time of treatment of an embryo and the manifestation of adverse effects. For example, during the first year after birth, offspring developed from blastocysts exposed to MNU in vitro had a threefold higher crude mortality rate than offspring developed from control blastocysts exposed to solvent. This point is central to an understanding of the 'large offspring syndrome', first alluded to by Willadsen (1989), and one of the principal reasons for current practical interest in the early regulation of mammalian development. At first, this phenomenon was considered to be an effect of nuclear transfer itself. However, it later became clear that the problem could arise from mere culture of embryos. The sporadic nature of the problem has made experimental investigation of it difficult and therefore survey studies and data from large-scale field studies have been exceptionally useful in the now extensive attempts to explain its causes. Recent reviews of the topic include those of Walker et al.
(1996), Rieger (1998), Robinson et al. (1999) and the several papers presented at a symposium in Maastricht in January 2000 (Barker, 2000; Barnes, 2000; Bavister, 2000; Boerjan et al., 2000; Kruip et al., 2000; Ménézo et al., 2000; van der Lende et al., 2000; van Wagtendonk-de Leeuw et al., 2000; Young and Fairburn, 2000).

Thus, since the 1960s, attitudes towards embryos and their precocious activities and susceptibilities have changed. This change in attitude has coincided with technical advances in embryo transfer and manipulation, and has helped in the investigation into how embryos need to be treated in vitro, and how mistreatment might compromise development, despite previous views to the contrary.

\section{Historical attitudes to the effects of nutrition on the conceptus}

By the time (1908) that Minot was publishing his 29 years of research into the fundamental aspects of growth in utero described above, more applied work on the importance of nutrition to fetal and neonatal development in humans and animals was also in progress. Paton (1903) used guinea-pigs to model the malnutrition of the poor in Edinburgh and showed '...that the size of the offspring depends very directly upon the diet and nutrition of the mother during pregnancy'. Walter Heape (1906), '....actuated by the desire to draw closer together two classes of workers in the great field of Biology, the Practical Breeder and Scientific Biologist...', considered that nutritional studies had been sadly neglected and that they would be essential if the quality of British livestock was to be improved. Current practical interest in early embryology stems largely from Heape's first successful embryo transfer, and it was his view that ' $\ldots$ it is the functional condition of the generative organs which require investigation; knowledge... of the intimate physical relation of the embryo to the mother, and all the intricate physiological phenomena connected with the prenatal and post-natal nutrition of the embryo that are here concerned; and it is work from which great benefit would undoubtedly be derived'.

The advent of the practical use of artificial insemination on the farm - another field to which Heape devoted much energy - made it possible for Walton and Hammond (1938) to undertake their classical studies of the respective roles of genetics and uterine environment on fetal growth. Taking advantage of the enormous size range encountered in various horse breeds, they used reciprocal crosses between large Shire horses and small Shetland ponies to show that maternal regulation of fetal growth was very marked and obscured any genetic differences. However, genetic effects made their appearance after weaning. With the foals on similar diets, the crosses from the Shire mares grew much less rapidly than pure Shire foals, whereas those from the Shetland dams grew much more rapidly than pure Shetlands. An equilibrium was attained at about 18 months of age, when the growth rates of the hybrids and the pure Shetlands remained constant so that the differences 


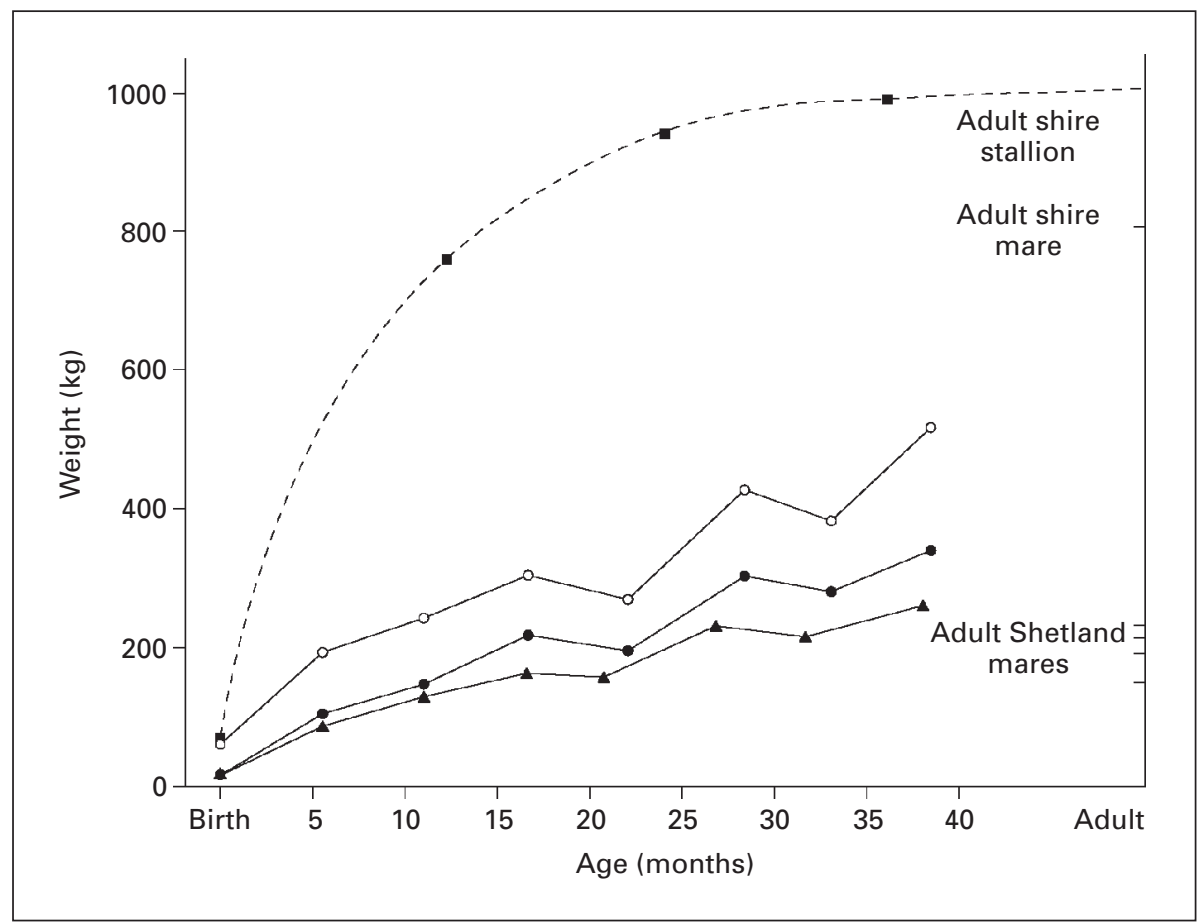

Fig. 4. Growth of foals resulting from: (O) Shetland-Shire cross from Shire dam; Shetland-Shire cross from Shetland dam; $(\boldsymbol{\Delta})$ pure Shetland; $(\boldsymbol{\square})$ pure Shire. (Redrawn from Walton and Hammond 1938.)

between the reciprocal crosses persisted into adulthood (Fig. 4). Walton and Hammond (1938) suggested that the mechanisms of maternal regulation might be maternal regulation of fetal nutrition, maternal hormonal control or cytoplasmic inheritance. The great influence of their work on the investigation of fetal growth has been discussed in a broad zoological context by McKeown et al. (1976).

The approach of Walton and Hammond to differentiating between genetic and nutritional effects on horse fetuses in utero has since been extended by embryo transfer between other breeds of horse of widely different size (Tischner, 1987; Wilsher and Allen, 2000). Wilsher and Allen (2000) used stereological estimates of feto-maternal contact density as a gauge of fetal nutrition.

After the pioneering experiments and advocacy of Paton (1903) and Heape (1906), respectively, maternal dietary effects on fetal growth and neonatal development in man and animals again became central to discussions at the 1974 Ciba symposium (Elliott and Knight, 1974) and at the symposia of the Nutrition Society in 1977 (for example, see Williams, 1977) and 1997. At the 1997 symposium, the enormous contributions to the field by both McCance and Widdowson were honoured (Dauncey, 1997). The topic has been comprehensively reviewed by Robinson et al. (1999).

In humans, the effects of famine, like those of diethylstilboestrol (DES), can also be transgenerational (Lumley, 1992). Therefore, it would be worthwhile to monitor offspring produced from embryos manipulated in vitro that survive despite initial abnormalities, especially oversize, through their reproductive years and into the next generation.

A particularly elegant experimental use of 'cloning' (that is, embryo bisection) extended work on the genetic and maternal effects on the fleece reviewed by Lawson (1977) to show how fetal nutrition can affect wool production and quality in sheep (Kelly et al., 1996). Lawson (1977) describes the earliest embryo transfer experiments to show how the development of very young (day 4) ovine embryos is influenced by the maternal environment, which in turn is affected by progesterone concentrations. In cattle, at least, the relationship between progesterone concentrations in milk and pregnancy indicates that the dialogue between the embryo and the endocrine system of the mother begins well before the 'critical stage' for the recognition of pregnancy (Lamming et al., 1989). Therefore, the reciprocity of the relationship between the mother and embryo - the uterine environment controlling embryonic development at the same time as it is controlled by embryonic development makes the distinction between genetic and environmental effects on the process rather arbitrary.

\section{Potential lessons from comparative studies}

Just as the new reproductive techniques can be considered to be rooted in comparative studies of reproductive biology, they can be predicted to benefit from investigations in as 
(a)

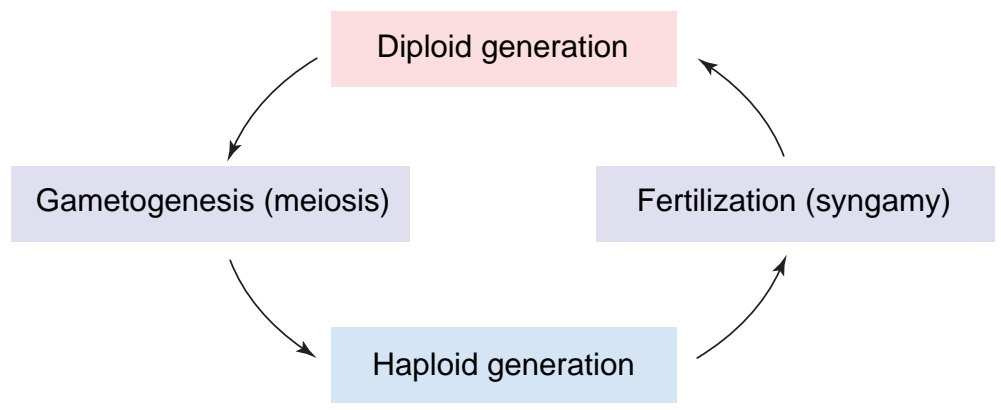

(b)

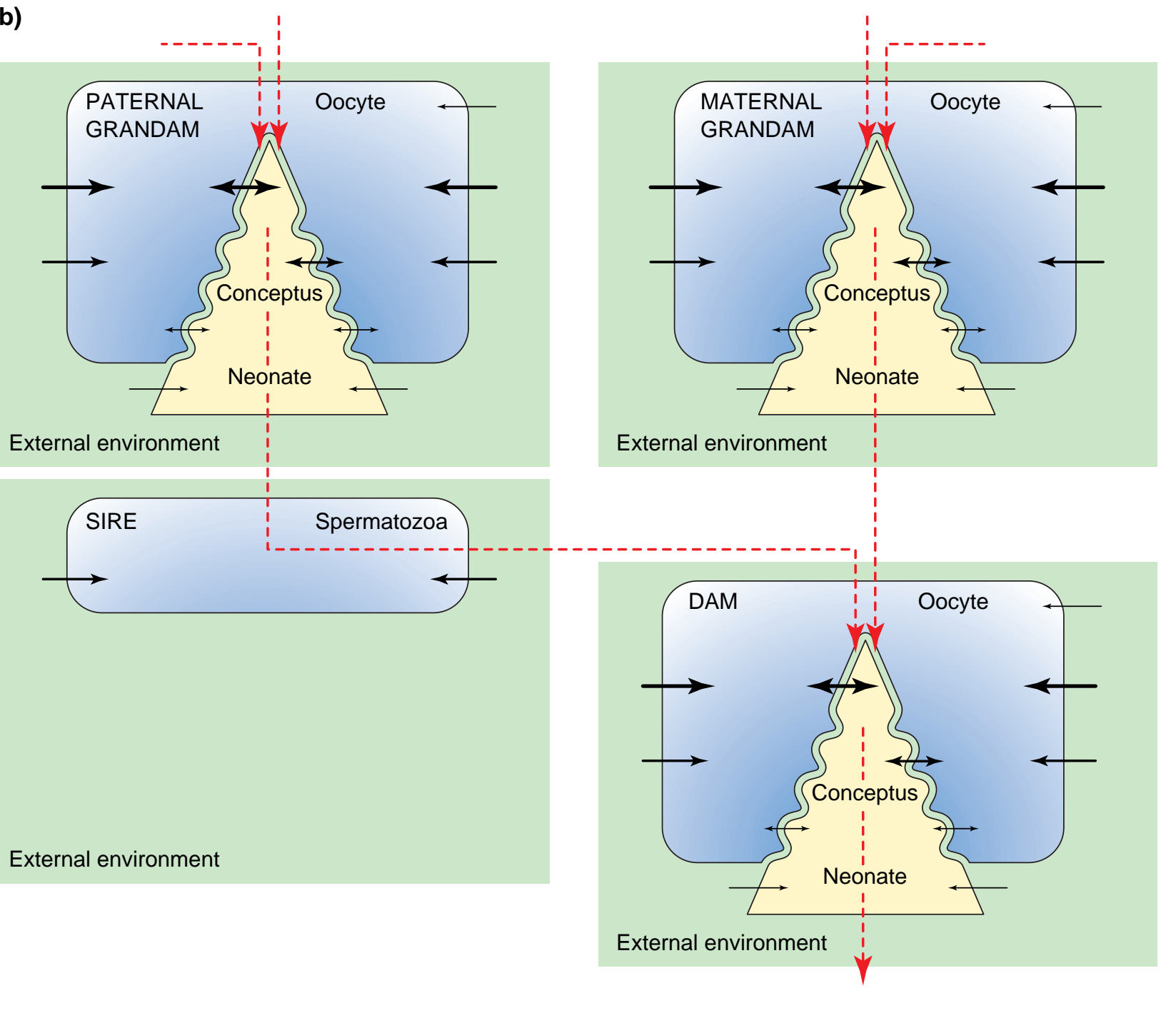

Fig. 5. Six principles underlying current and future experimental investigation of conceptus growth. (a) (1) Conceptus growth and development, initiated at fertilization, occupy a relatively brief segment of the life cycle comprising haploid and diploid generations. (b) (2) Growth of the diploid conceptus (and neonate) (triangles) is under genetic and environmental control and requires synchrony of developmental events in the conceptus and mother (interlocking waved borders between the conceptus and mother). (3) This synchrony depends on two-way interaction between the mother and conceptus (double-ended arrows). (4) Maternal (as well as paternal and neonatal) environments are also influenced by external factors, notably diet and management (arrows) (McEvoy et al., 2001). (5) Events leading to the haploid segment of the life cycle (gametogenesis, broken red lines) begin in utero and are therefore subject to parental and grandparental (trans-generational) influences. Genetic imprinting is an important process that depends on the parental origin of particular alleles. (6) Perturbations of the environments that cause epigenetic change can affect gametogenesis, embryogenesis and synchrony. Such 
many species as proves practicable in the future (Betteridge, $2000,2001)$. The mammals in which the new reproductive techniques are practised represent an extremely small fraction of the class as a whole (Betteridge, 1995). There are many reproductive strategies involving different forms of conceptus development that could well be relevant to the production and manipulation of embryos in farm and laboratory animals as well as in humans.

In terms of development, one of the earliest (and most contentious) features of comparative interest is oocyte polarity. Signs of oocyte polarity vary widely among species (Betteridge, 1995) and the regional distribution of ooplasmic factors may be important to the outcome of intracytoplasmic sperm injection (ICSI) (Fulka et al., 1998). Although there is experimental evidence against any effect of region on the ability of divided mouse blastomeres to produce young (Zernicka-Goetz, 1998), Gardner (1999a) argues that it is not yet conclusive. However, there is clear evidence and general agreement that embryonic and fetal axes are established very early in development (Gardner, 1999b, 2000; Ciemerych et al., 2000), even at the time of fertilization in mice (Piotrowska and Zernicka-Goetz, 2001). It would seem opportune and feasible to extend these studies into the farm species in which embryo production and manipulation in vitro are now so well established. An advantage of using the embryos of farm species is that, unlike mouse embryos, they do not become '...inaccessible to study at... the time of overt axis formation' (Pederson, 2001).

The sex of an embryo can affect its reaction to, or tolerance of, culture in vitro. Male embryos or fetuses of several species, including mice, cattle, pigs and humans, develop more rapidly than their female sibs (Xu et al., 1992; Mittwoch, 1993, 1998; Cassar et al., 1994). The mechanisms underlying this phenomenon remain difficult to understand, particularly in view of the fact that the effect is seen even before activation of the embryonic genome (Yadav et al., 1993). Investigation of such differential effects of a well-defined genetic difference offers a useful model for understanding how early development can become perturbed in vitro. The mysterious ways in which sex ratios depend on the ovary from which oocytes originate in gerbils (Clark et al., 1994), and female fetuses are selectively lost after maternal treatment with melatonin before blastocyst implantation in meadow voles (Gorman et al., 1994) must also be of relevance to the outcome of embryo manipulation and transfer.

Virtually all researchers working with new reproductive techniques have learned mammalian embryology in species in which the embryo proper develops from a welldefined inner cell mass. However, in some eutherian and many metatherian species, the differentiation of embryonic cells is from unilaminar blastocysts (for references, see Betteridge, 1995). Understanding how this form of differentiation occurs may have a bearing on attempts to generate embryonic stem cells and could now be a practical proposition, given the availability of colonies of laboratory marsupials.

Even wild animals are not entirely inaccessible. Roe deer abound in many European countries and could be used to further understanding of the physiology of embryonic diapause. Such work would surely benefit embryo culture techniques in domestic ungulates.

One of the most intriguing puzzles in mammalian embryology must surely be the mechanisms by which armadillos routinely produce identical quadruplets or octuplets. These animals are relatively easy to obtain in the southern states of the USA and deciphering their secret could be of major importance for the limited cloning of farm livestock.

The unusual mechanisms of conceptus expansion in horses (for review, see Betteridge, 2000) seem to involve movement of water and solutes in ways likely to be relevant to embryo cryopreservation, and not only in horses. Comparisons of early conceptus development in horses and ruminants with regard to allantois development could also be instructive. Derangement of allantoic development seems to be a factor in embryonic loss in cattle (Peterson et al., 2000) and allantoic mesenchyme evidently plays a key role in determining the invasiveness of chorionic girdle cells in horses (Stewart et al., 2000). In addition, a gene controlling allantoic (and primordial germ cell) development has been identified in mice (Lawson et al., 1999; McLaren, 1999). Equine conceptuses are much easier to collect during the time of allantoic development than are those of ruminants and may constitute a unique model in which to pursue studies of the importance of the allantois in early pregnancy and in toxicological investigations (Maranghi et al., 1998).

The sex of the intrauterine neighbours of a pig fetus can profoundly affect its phenotype and subsequent reproductive capacity (for example, see Drickamer et al., 1997). The polytocous laboratory animals are likely to provide useful models in which to study the mechanisms of such effects and may also alert us to other problems of practical significance in livestock. In gerbils, for example, the uterine position of a female affects the sex ratios in her own subsequent litters (Clark and Galef, 1995). Although paternal behaviour towards a litter is of no concern in domestic animals, the mechanisms underlying its control by uterine position in some polytocous species might be significant (Clark et al., 1998).

environmental effects can be incurred at any point along the broken red lines and may be manifested immediately or after a delay. Manipulation of gametes and embryos in vitro is an obvious example of a potentially adverse influence of this kind. Others, particularly dietary effects, are also important. The vulnerability of the conceptus to epigenetic change is greater at the onset of its development than at later stages (denoted by the thickness of the arrows and double-headed arrows) (Sinclair et al., 2000; Young et al., 2001). 


\section{Conclusion}

A century's worth of painstaking exploration by our forebears has brought us to the point where we can readily accept that the circumstances under which the mammalian embryo is conceived and incubated, in vivo or in vitro, has permanent effects on its development before and after birth. Fundamental principles have been established (Fig. 5) and investigation of the mysteries of normal and abnormal conceptus development using all the powerful techniques now available continues. As scientists, we can take pride in this collective effort and be inspired to continue it. This paper is respectfully dedicated to the memory of $\mathrm{Dr}$ Francesca Stewart, whose comparative studies of early development in the horse, and interest in James Cossar Ewart, were inspirational.

The author thanks Kevin Sinclair for numerous suggestions during the preparation of this manuscript, and NSERC Canada for financial support.

\section{References}

Key references are identified by asterisks.

Alexander G (1974) Birth weight of lambs: influences and consequences. In Size at Birth Ciba Foundation Symposium 27 (new series) pp 215-245 Eds K Elliott and J Knight. Elsevier Excerpta Medica North Holland, Amsterdam

Allen WR (1982) Immunological aspects of the endometrial cup reaction and the effect of xenogeneic pregnancy in horses and donkeys Journal of Reproduction and Fertility Supplement 31 57-94

Anon (1896) Telegony Veterinary Journal 43 297-300

Anon (1991) Prevention of neural tube defects: results of the Medical Research Council Vitamin Study. MRC Vitamin Study Research Group Lancet 338 131-137

Barker DJP (2000) In utero programming of cardiovascular disease Theriogenology 53 555-574

Barnes FL (2000) The effects of the early uterine environment on the subsequent development of embryo and fetus Theriogenology 53 649-658

Bavister BD (2000) Interactions between embryos and the culture milieu Theriogenology 53 619-626

Betteridge KJ (1981) An historical look at embryo transfer Journal of Reproduction and Fertility 62 1-13

Betteridge KJ (1995) Phylogeny, ontogeny and embryo transfer Theriogenology 44 1061-1098

Betteridge KJ (2000) Comparative aspects of equine embryonic development Animal Reproduction Science 60/61 691-702

Betteridge KJ (2001) Enigmas and variations among mammalian embryos Reproduction in Domestic Animals 36 37-40

Betteridge KJ and Laing JA (1970) The diagnosis of pregnancy. In Fertility and Infertility in the Domestic Animals 2nd edn pp 81-127 Ed. JA Laing. Baillière, Tindall and Cassell, London

Bielanski W, Ewy Z and Pigoniowa H (1955) [Preliminary investigations on differences in endocrine secretion in mares which are in foal to the stallion and to the ass] Folia biologica 3 19-30 (Animal Breeding Abstracts 24 43)

Boerjan ML, den Daas JHG and Dieleman SJ (2000) Embryonic origins of health: long term effects of IVF in human and livestock Theriogenology 53 537-547

Bouin P and Ancel P (1903) Sur la signification de la glande interstitielle du testicule embryonnaire Comptes rendus des séances de la Société de biologie et de ses filiales 55 1682-1684

Cassar G, King WA and King GJ (1994) Influence of sex on early growth of pig conceptuses Journal of Reproduction and Fertility 101 317-320
Ciemerych MA, Mesnard D and Zernicka-Goetz M (2000) Animal and vegetal poles of the mouse egg predict the polarity of the embryonic axis, yet are nonessential for development Development 127 3467-3474

Clark MM and Galef BG, Jr (1995) A gerbil dam's fetal intrauterine position affects the sex ratios of litters she gestates Physiology and Behavior $\mathbf{5 7}$ 297-299

Clark MM, Ham M and Galef BG, Jr (1994) Differences in the sex ratios of offspring originating in the right and left ovaries of Mongolian gerbils (Meriones unguiculatus) Journal of Reproduction and Fertility 101 393-396

Clark MM, Vonk JM and Galef BG, Jr (1998) Intrauterine position, parenting, and nest-site attachment in male Mongolian gerbils Developmental Psychobiology 32 177-181

Conlon I and Raff M (1999) Size control in animal development Cell 96 235-244

Cupo A, Ménézo Y and Bueno L (1987) Enkephalin production by the corpus luteum Neuropeptides 9 237-245

Dauncey MJ (1997) From early nutrition and later development ... to underlying mechanisms and optimal health British Journal of Nutrition 78 Supplement 2 S113-S123

Drickamer LC, Arthur RD and Rosenthal TL (1997) Conception failure in swine: importance of a female's birth litter and tests of other factors Journal of Animal Science 75 2192-2196

*Elliott K and Knight J (Eds) (1974) Size at Birth Ciba Foundation Symposium 27 (new series) Elsevier Excerpta Medica North Holland, Amsterdam

Ewart JC (1879) Aberdeen University. Introductory Lecture offprint in Special Collections of the University of Edinburgh Library, General 132

Ewart JC (1897) A Critical Period in the Development of the Horse Adam and Charles Black, London

Ewart JC (1899) The Penycuik Experiments Adam and Charles Black, London

Ewart JC (1915) Studies of the development of the horse I. The development during the third week Transactions of the Royal Society of Edinburgh $\mathbf{5 1}$ 287-329

Fulka J, Jr, Kárníková L and Moor RM (1998) Oocyte polarity, ICSI, cloning and related techniques Human Reproduction 13 3303-3305

Gaeth AP, Short RV and Renfree MB (1999) The developing renal, reproductive and respiratory systems of the African elephant suggest an aquatic ancestry Proceedings National Academy of Science USA 96 5555-5558

Gardner RL (1999a) Scrambled or bisected mouse eggs and the basis of patterning in mammals Bioessays 21 271-274

Gardner RL (1999b) Polarity in early mammalian development Current Opinion in Genetics and Development 9 417-421

Gardner RL (2000) Flow of cells from polar to mural trophectoderm is polarized in the mouse blastocyst Human Reproduction 15 694-701

Gorman MR, Ferkin MH and Dark J (1994) Melatonin influences sexspecific prenatal mortality in meadow voles Biology of Reproduction $\mathbf{5 1}$ 873-878

Greep RO (1973) A vista of research on the mammalian gonadotropins Biology of Reproduction 8 2-10

Hamburger C (1965) Historical introduction. In Gonadotropins: Physicochemical and Immunological Properties pp 2-10 Eds GEW Wolstenholme and J Knight. J and A Churchill, London

Hammond J (1939) Physiological aspects of bovine sterility Proceedings of the 57th Annual Congress of the National Veterinary Medical Association of Great Britain and Northern Ireland pp 2-6

Hayflick L (2000) New approaches to old age Nature 403365

Heape W (1906) The Breeding Industry: its Value to the Country, and its Needs Cambridge University Press, Cambridge

Hight GK and Jury KE (1969) Lamb mortality in hill country flocks Proceedings of the New Zealand Society of Animal Production 29 219-232

Holm LW (1967) Prolonged pregnancy Advances in Veterinary Science and Comparative Medicine 11 159-205

Holm LW and Short RV (1962) Progesterone in the peripheral blood of Guernsey and Friesian cows during prolonged gestation Journal of Reproduction and Fertility 4 137-141 
*Iannaccone PM (1984) Long-term effects of exposure to methylnitrosourea on blastocysts following transfer to surrogate female mice Cancer Research 44 2785-2789

Kelly RW, Macleod I, Hynd P and Greeff J (1996) Nutrition during fetal life alters annual wool production and quality in young Merino sheep Australian Journal of Experimental Agriculture 36 259-267

Kent HA, Jr (1978) Inhibition of ovulation by synthetic samples of the tetrapeptide originally isolated from hamster embryos Biology of Reproduction 19 785-789

Kruip TAM, Bevers MM and Kemp B (2000) Environment of oocyte and embryo determines health of IVP offspring Theriogenology 53 611-618

Lamming GE, Darwash AO and Back HL (1989) Corpus luteum function in dairy cows and embryo mortality Journal of Reproduction and Fertility Supplement 37 245-252

Lawson KA, Dunn NR, Roelen BAJ, Zeinstra LM, Davis AM, Wright CVE, Korving JPWFM and Hogan BLM (1999) Bmp4 is required for the generation of primordial germ cells in the mouse Genes and Development 13 424-436

Lawson RAS (1977) Research applications of embryo transfer in sheep and goats. In Embryo Transfer in Farm Animals: a Review of Techniques and Applications Monograph No. 16 pp 72-78 Ed. KJ Betteridge. Canada Department of Agriculture, Ottawa

Leese HJ, Tay JI, Reischl J and Downing SJ (2001) Formation of Fallopian tubal fluid: role of a neglected epithelium Reproduction 121 339-346

*Liggins GC, Kennedy PC and Holm LW (1967) Failure of initiation of parturition after electrocoagulation of the pituitary of the fetal lamb American Journal of Obstetrics and Gynecology 98 1080-1086

Longo LD (2000) Classic pages in the American Journal of Obstetrics and Gynecology American Journal of Obstetrics and Gynecology 182 473-474

Lumley LHT (1992) Decreased birthweights in infants after maternal in utero exposure to the Dutch famine of 1944-1945 Paediatric and Perinatal Epidemiology 6 240-253

McEvoy TG, Robinson JJ, Ashworth CJ, Rooke JA and Sinclair KD (2001) Feed and forage toxicants affecting embryo survival and fetal development Theriogenology 55 113-129

*McKeown T, Marshall T and Record RG (1976) Influences on fetal growth Journal of Reproduction and Fertility 47 167-181

McLaren A (1999) Signaling for germ cells Genes and Development 13 373-376

Maranghi F, Macri C, Ricciardi C, Stazi AV and Mantovani A (1998) Evaluation of the placenta: suggestions for a greater role in developmental toxicology Advances in Experimental Medicine and Biology 444 129-136

Marshall FHA (1910) The Physiology of Reproduction Longmans Green, London

Ménézo YJR, Veiga A and Pouly JL (2000) Assisted reproductive technology (ART) in humans: facts and uncertainties Theriogenology 53 599-610

Minot CS (1908) The Problem of Age, Growth, and Death GP Putnam's Sons, New York

Mittwoch U (1993) Blastocysts prepare for the race to be male Human Reproduction 8 1550-1555

Mittwoch U (1998) Phenotypic manifestations during the development of the dominant and default gonads in mammals and birds Journal of Experimental Zoology 281 466-471

Moule GR, Jackson MNS and Young RB (1956) Lambing losses Queensland Agricultural Journal 82 345-354, 399-401

Nathanielsz PW (1998) Comparative studies on the initiation of labor European Journal of Obstetrics, Gynecology and Reproductive Biology 78 127-132

Neumann F, Elger W and Steinbeck H (1969) Drug-induced intersexuality in mammals Journal of Reproduction and Fertility Supplement 7 9-24

Paton N (1903) The influence of diet in pregnancy on the weight of the offspring Lancet July 4 21-22

Pedersen RA (2001) Sperm and mammalian polarity Nature 409 473-474

Perry JS (Ed.) (1969) Intersexuality Journal of Reproduction and Fertility Supplement 7

Peterson AJ, McMillan WH and Thompson JG (2000) Various allantoic pathologies are associated with malformations of allantoic development of the IVP embryo Proceedings of the 14th International Congress on Animal Reproduction, Stockholm Abstract 5:6, p. 158

Piotrowska K and Zernicka-Goetz M (2001) Role for sperm in spatial patterning of the early mouse embryo Nature 409 517-521

Record RG, Gibson JR and McKeown T (1952) Foetal and infant mortality in multiple pregnancy Journal of Obstetrics and Gynaecology of the British Empire 59 471-482

Rieger D (1998) Effects of the in vitro chemical environment during early embryogenesis on subsequent development Archives of Toxicology Supplement 20 121-129

Robinson JJ (1977) The influence of maternal nutrition on ovine fetal growth Proceedings of the Nutrition Society 36 9-16

Robinson JJ, Sinclair KD and McEvoy TG (1999) Nutritional effects on foetal growth Animal Science 68 315-331

Sinclair KD, Young LE, Wilmut I and McEvoy TG (2000) In vitro overgrowth in ruminants following embryo culture: lessons from mice and a warning to men Human Reproduction Supplement 5 68-86

Stewart F, Mathias S and Allen WR (2000) The differentiation of invasive trophoblast cells in the equine placenta Journal of Reproduction and Fertility Abstract Series 25 Abstract 16

Tischner M (1987) Development of Polish-pony foals born after embryo transfer to large mares Journal of Reproduction and Fertility Supplement 35 705-709

van der Lende T, de Loos FAM and Jorna T (2000) Postnatal health and welfare of offspring conceived in vitro: a case for epidemiological studies Theriogenology $\mathbf{5 3}$ 549-554

van Niekerk CH and Gerneke WH (1966) Persistence and parthenogenetic cleavage of tubal ova in the mare Onderstepoort Journal of Veterinary Research 31 195-232

van Wagtendonk-de Leeuw AM, Mullaart E, de Roos APW, Merton JS, den Daas JHG, Kemp B and de Ruigh L (2000) Effects of different reproduction techniques: $\mathrm{AI}, \mathrm{MOET}$ or IVP, on health and welfare of bovine offspring Theriogenology 53 575-597

Walker SK, Hartwich KM and Seamark RF (1996) The production of unusually large offspring following embryo manipulation: concepts and challenges Theriogenology 45 111-120

Walton A and Hammond J (1938) The maternal effects on growth and conformation in Shire horse-Shetland pony crosses Proceedings of the Royal Society of London Series B 125 311-335

Widdowson EM (1974) Immediate and long-term consequences of being large or small at birth: a comparative approach. In Size at Birth Ciba Foundation Symposium 27 (new series) pp 65-82 Eds K Elliott and J Knight. Elsevier Excerpta Medica North Holland, Amsterdam

Willadsen SM (1989) Cloning of sheep and cow embryos Genome 31 956-962

Williams RB (1977) Trace elements and congenital abnormalities Proceedings of the Nutrition Society 36 25-32

Wilsher S and Allen WR (2000) Influence of maternal size, age and parity on placental and fetal development in the horse Journal of Reproduction and Fertility Abstract Series 25 Abstract 17

*Wolstenholme GEW and O'Connor M (Eds) (1969) Foetal Autonomy J and A Churchill, London

Xu KP, Yadav BR, King WA and Betteridge KJ (1992) Sex-related differences in developmental rates of bovine embryos produced and cultured in vitro. Molecular Reproduction and Development 31 249-252

Yadav BR, King WA and Betteridge KJ (1993) Relationships between the cleavage and the chromosomal complement, sex, and developmental rates of bovine embryos generated in vitro. Molecular Reproduction and Development 36 434-439

Young LE and Fairburn HR (2000) Improving the safeties of embryo technologies: possible role of genomic imprinting Theriogenology $\mathbf{5 3}$ 627-648

Young LE, Fernandes K, McEvoy TG, Butterwith SC, Gutierrez CG, Carolan C, Broadbent PJ, Robinson JJ, Wilmut I and Sinclair KD (2001) Epigenetic change in IGF2R is associated with fetal overgrowth after sheep embryo culture Nature Genetics 27 153-154

Zernicka-Goetz M (1998) Fertile offspring derived from mammalian eggs lacking either animal or vegetal poles Development 125 4803-4808 